the so-called mechanical treatment of waters of these types is very liable to bring about this troublesome discoloration.

It may be noted here that both these waters examined were of low mineral content and highly colored by peaty matter. It would be of interest to follow this matter further with various other types.

These figures are in excellent accord with the electrolytic theory of corrosion and illustrate an easy means for investigating this subject. A graphic representation could be presented with the aid of further figures which would be very interesting.

Chemcal Laboratory, Defartment of Agriculture EXPERIMENTAL FARM, OTTAWA, ONT.

\section{SOME EXPERIMENTS ON THE CONVERSION OF LONG- LEAF PINE TO PAPER PULP BY THE SODA AND SULFATE PROCESSES}

By SIDNEY D. WELIS

\section{INTRODUCTION}

During $\mathrm{x} 9 \mathrm{I} 2$ the Forest Service in cooperation with the University of Wisconsin undertook a series of experiments on longleaf pine, Pinus palustris, with the following objects:

I. To study what influence the variable cooking conditions have in the sulfate process of pulp-making.

2. To determine the suitability of longleaf pine for paper pulp.

3. To compare the sulfate process with the soda process.

This work has been only partially completed but since there is urgent demand for information on the adaptability of longleaf pine, or southern pine as it is more commonly called, for the manufacture of paper pulp, it has been thought advisable to give what indications our work has so far made manifest.

Longleaf pine was chosen on account of the large quantities of this wood that are being wasted in the lumber operations of the southern states and also because many logs are at present being sawed into lumber at little or no profit on account of their small diameter which would be of admirable size for pulpwood. Furthermore, the large amount of resinous matter in this wood made it desirable as an extreme test of a cooking process and the long, thick-walled fibers of the wood assured a strong pulp if it could be produced without a too drastic treatment.

\section{EXPERIMENTAL PROCEDTRE}

The cooking operations in this work were conducted in two forms of digesters. The first form consisted of a small rotary autoclave of about 2-gallon capacity which was heated with Bunsen burners. The other form was a vertical digester of 60-gallon capacity, heated by direct steam. The greater portion of the work was accomplished in the former and in all I45 cooks made. The data obtained in these cooks were used in determining the conditions for the larger digester in which I 9 cooks were made to obtain conditions more nearly comparable with those used in commercial practice.

1 Paper presented at the 48 th Meeting of the A. C. S., Rochester, September 8-14, 1913.
The wood used was procured in Louisiana and Mississippi, and was fairly average in rate of growth, size, and content of resinous matter. It was freed from bark and reduced to chips five-eighths of an inch long with the grain. These chips were allowed to become air-dry and were thoroughly mixed and sifted to remove any dirt and small pieces.

The cooking liquors were made up by dissolving the required amounts of commercial caustic soda, sodium sulfide, Glauber's salt, and soda ash to produce solutions of the desired concentration of each of these chemicals.

In studying the influence of the variable factors entering into the cooking operation the small autoclave was used. The effect that any one variable condition exerted was determined by a series of cooks made varying the condition under observation, and maintaining the other conditions as nearly identical as possible in each cook. The effects were ascertained by determining the yield of pulp and carefully treating the pulp in a hollander beating engine to develop a stuff capable of producing as strong a sheet as possible when made into paper. The quality and color of the pulps were judged by inspection, feel, amount of beater treatment necessary, and the strength and wearing qualities of the paper produced.

THE EFFECTS OF VARYING THE AMOUNTS OF CHEMICAIS

The effect of varying the caustic soda or sodium sulfide was a decrease in yield and a lighter colored pulp with an increase in either one or both of the chemicals. Caustic soda was found to be about twice as drastic in its action as sodium sulfide and with the same yield the pulp produced by the former was lighter than that produced by the latter. The yields, however, do not decrease directly in proportion to the amounts of chemical used, and between 30 and 50 pounds of caustic per 100 pounds of chips the decrease in yield is much less for equal steps than below or above these amounts. The disagreeable odor caused by the production of mercaptans increased with the increase of the sodium sulfide, and was much more noticeable where the larger proportions of this chemical were used.

The sodium carbonate and sulfate present in the cooking liquor produced no very apparent effect except where the former was present in relatively large amounts when a retardation in the action of the other chemicals present was noticeable. Enough cooks were not made, however, to definitely establish this indication.

THE EFFECT OF VARYIÄG THE PRESSURE, DURATION OF COOKING AND CONCENTRATIONS

The effect of increasing any one of these variables was to increase the severity of the cooking action attainable with the same quantity of cooking chemicals. With any combination of the above conditions there is a definite amount of chemical necessary to produce a pulp of the best quality and it is possible to use a wide range of conditions to produce approximately the same result. 


\section{SEMI-COMMERCIAL COOKS}

In the cooks in the large digester the object sought was to obtain the best quaity of pulp. It was found that easily-bleaching pulps could not be obtained without using a very drastic digestion with a high percentage of alkali, and that the pulps produced were very low in yield and extremely soft and weak. It was, therefore, decided to devote attention toward producing the strongest pulps possible, and treat these pulps in the beater to make the highest grade of "Kraft." Although the strength of the paper was constantly considered, the question of yield was also very important and the best cooks were determined with these two objects in view.

The best cooks secured were made under the following conditions:

Caustic soda charged per 100 pounds bone dry chips. pounds....... 15.0 Sodium sulfide charged per 100 pounds bone-dry chips, pounds . . . . 7.5 Initial concentration caustic soda in cooking liquor, grams per liter.... 26.5 Initial volune liquor per pound of chips, gallon............. 0.68

Total duration of cook hours .................... 3.5

Duration of cook at maximum steam fressure, hours.......... 3.0

Maximum steam pressure, pounds per square inch ........... 100.0

The yields of crude pulp under these conditions were 49 per cent of the weight of the wood and the with these pulps using the same or an even less consumption of power and in much less time.

\section{SODA COOKS}

To compare the soda process with the sulfate process in cooking longleaf pine several soda cooks were made. It was found that soda pulps could be made that would produce paper capable of resisting bursting pressure to the same degree as the best paper made from sulfate pulp but the wearing qualities were not nearly as good and the yields were from 5 to ro per cent less. The unbeaten pulps were soft and fluffy for even slightly undercooked pulps, and although they could be hardened in the beater the treatment was longer, and much greater care had to be exercised to avoid cutting the fibers. Furthermore, although a fairly good grade of kraft can be made of sulfate pulp with a yield of 60 per cent, soda pulp produced with that yield would be so undercooked and brittle that only very poor wrapping could be produced. Moreover, it was found necessary to cook soda pulp at least 6 hours to secure good results while in the sulfate process $3 \frac{1 / 2}{2}$ hours were found sufficient. Thus in the latter process the same digester capacity would produce two-thirds more pulp per day.

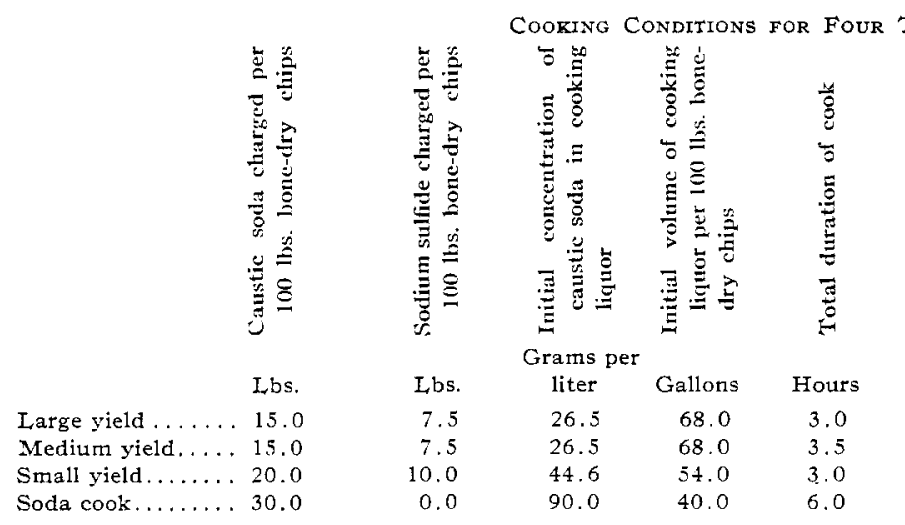

strength of the paper produced as determined on the Mullen tester was 9 pounds per thousandth of an inch of thickness. An average sheet of 0.005 of an inch tested 45 pounds and weighed 45 pounds per ream of 500 sheets 24 inches by 36 inches. Not only was the paper exceptionally strong but it was very resistant to wear and folding. The latter fact is apparent by some tests made on it in a Schopper Folding Tester in which it withstood I 200 double folds before breaking.

The pulps under these conditions were very chippy when blown but the chips were very soft, had no hard hearts and were readily broken $u p$ in the beater. An ordinary hollander with steel fly bars was used and the pulp was beaten two hours at light brush, four hours at stiff brush, and one-half hour was spent in lowering the roll from one stage to the other.

Stronger papers than these were produced but the yields fell off considerably. Yields up to $6 \mathrm{I}$ per cent were obtained but the strength fell off more than could be compensated by using proportionately heavier paper. It is very probable that with basalt lava beater rolls a stronger paper could have been produced

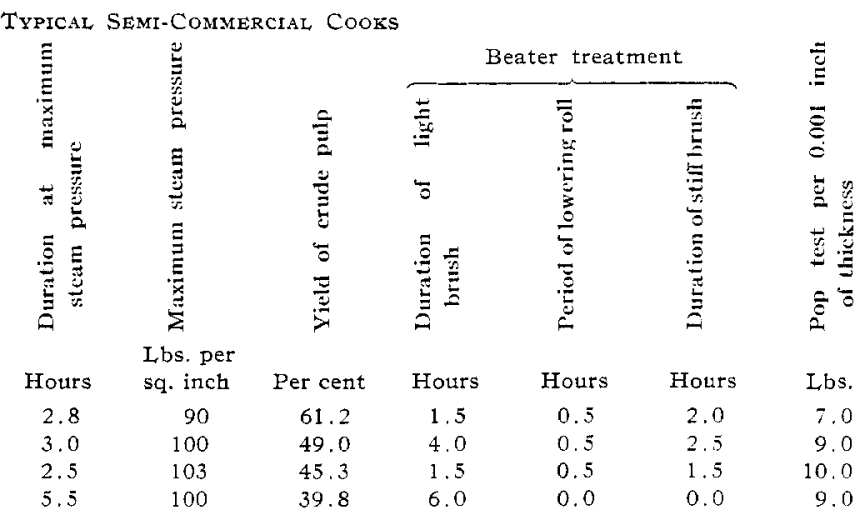

GENERAL CONCLUSIONS

Although the experiments performed in this investigation are only a portion of what are contemplated they seem to make apparent the following facts:

I. That longleaf pine is well adapted for the manufacture of natural-color kraft pulps and papers.

II. That the sulfate process when applied to this wood affords pulps of better quality and higher yields than the soda process.

III. That kraft paper can be made from longleaf pine equal or superior in quality to the imported or domestic kraft papers now procurable.

IV. The high specific gravity of the wood insures a greater yield per cord to this wood than is possessed by any other commercially important pulpwood.

The data of these experiments given in greater detail is contained in a report entitled "The Utilization of Longleaf Pine for Paper Pulp" by H. E. Surface and R. E. Cooper which is now in press at the Government Printing Office.

FOREST PRODUCTS LABORATORY

Madison, Wisconsin 